\title{
Magnetic and Dynamic Mechanical Properties of Nd-Fe-B Composite Materials with Polymer Matrix
}

\author{
Aleksandar Grujić1, Jasna Stajić-Trošić1, Mirko Stijepović2,3 \\ Jasmina Stevanović ${ }^{1}$ and Radoslav Aleksić ${ }^{2}$ \\ ${ }^{1}$ Institute of Chemistry, Technology and Metallurgy, University of Belgrade \\ ${ }^{2}$ Faculty of Technology and Metallurgy, University of Belgrade \\ ${ }^{3}$ Department of Chemical Engineering, Texas A\&M University at Qatar \\ 1,2Serbia \\ ${ }^{3}$ Qatar
}

\section{Introduction}

At the end of the last century whole variety of technical-technological achievements occurred. Cars overflow the streets, air-conditions coated the facades, everyday life became unimaginable without computers and cell phones; kitchens are filled with assorted appliances, and industry has been improved and enforced by high technology in order to achieve higher manufacturing products, with less energy and manpower consumption. If a deeper look is taken, behind modern design exteriors, inside all of these appliances, it is noticeable that one of the key roles in their performance is engaged by permanent magnets. These materials have very important role as functional components within the wider spectra of contemporary devices in different industrial branches, as well as in the wider consumption. One of the most important applications of the permanent magnets are: spare parts in AC and DC engines production (Slusarek \& Dudzikowski, 2002), as well as synchronized motors, transformers, actuators, magnetic buffers, stationary fields, etc. (Gutfleisch et al., 2011). Information storage (hard discs), communications, medical appliances and scanners, automobile and aircrafts industries, could also be emphasized as important applications (Matsuura, 2006; Brown et al., 2002).

The nanocrystalline Nd-Fe-B alloys are one of the most superior magnetic materials with high value of maximum energy production (app 50 MGOe) (Herbst, 1991). Besides their high values of the remanence and coercivity, as well as relatively high Curie temperatures (app $312{ }^{\circ} \mathrm{C}$ ) (Sagawa et al., 1984) this type of magnetic alloys are identified suitable for research and further development of magnetic composite materials with polymer matrix, so called bonded magnets (Brown et al., 2006; Ma et al., 2002). Contemporary research in the field of magnetic composite materials on the basis of $\mathrm{Nd}-\mathrm{Fe}-\mathrm{B}$ alloys are directed into four basic directions: increase of magnetic energy, meaning optimisation of magnetic capacities; improving corrosion resistance; optimisation production process of process parameters; and reduction of the subtle rare earth content $(\mathrm{Nd})$, targeting decreasing the price of the final magnetic material, keeping high values of the maximum magnetic energy. Application of 
various process techniques in the production process of bonded magnets, gives the possibility for utilisation of various magnetic powder in combination with different polymeric materials as binding agent. Development of bonded technology, exploring the possibility of applications of various types of magnetic powder and polymeric matrices, testing of their influence, as well as the influence of the process parameters, to achieve optimal mechanical and magnetic capacities are in research focus during the last few years (Garrell et al., 2003; Lahelin et al., 2009). Research trend is reflected in development of bonded hybrid magnetic composite materials with improved dynamic mechanical capacities and noticeably lower cost due to the replacement of the expensive $\mathrm{Nd}-\mathrm{Fe}-\mathrm{B}$ magnetic powder with cheaper ferrite magnetic materials, achieving satisfying values of the maximum magnetic energy.

The objective of this chapter is to give more insight on the role of $\mathrm{Nd}-\mathrm{Fe}-\mathrm{B}$ particles on dynamic mechanical, thermal and magnetic properties of $\mathrm{Nd}-\mathrm{Fe}-\mathrm{B} /$ epoxy resin composite materials. Replacing one fraction of Nd-Fe-B with barium ferrite the hybrid composite materials with upgraded dynamic mechanical properties is produced. Interactions between employed magnetic powders and interactions between magnetic powders and polymer binder are considered. The advantage of DMA technique compared to the standard mechanical test methods is demonstrated. In addition, predictive mathematical models are employed to evaluate behaviour of composite. Results obtained with proposed mathematical models are in very good agreement with experimental values.

\section{Synthesis of Nd-Fe-B / epoxy resin composite materials}

There are several different process routes for bonded magnet production (Hamano, 1995; Gronefeld, 2002). The compression moulding is the most common technique utilized for materials with thermosetting polymer matrices. Composites with varied content of Nd-Fe-B particles in epoxy matrix from 15 to $95 \mathrm{wt} \%$ are produced by compression moulding under a pressure of $4 \mathrm{MPa}$ at room temperature, using a lab scale compression moulding press. Also, $\mathrm{Nd}-\mathrm{Fe}-\mathrm{B} /$ barium ferrite/epoxy resin composites as well as pure epoxy samples are obtained. The moulded samples are then allowed to cure under a moulding pressure for about 24 hours. The synthesis is carried out under conditions that avoid air bubbles in the mixture. No external magnetic field is used during the cure.

\subsection{Polymer binder}

As polymer matrix thermosetting epoxy system that is a combination of liquid mixture of Bisphenol A and Bisphenol $\mathrm{F}$ resins and cross linking agent (hardener), which cures fully at room temperature, is used. In terms of manufacture, the curing time of the matrix must be long enough for the polymer and magnetic alloy to be properly mixed, but shorter than required for the gravitational settling of the Nd-Fe-B particles. During curing, shrinkage should be minimal, and the thermal expansion of both polymer matrix and $\mathrm{Nd}-\mathrm{Fe}-\mathrm{B}$ should be comparable. Applying these criteria, the medium hard epoxy resin has the following properties: tensile strength $\sim 58 \mathrm{MPa}$, elongation $\sim 2.8 \%$, compression strength $\sim 96 \mathrm{MPa}$, flexural strength $\sim 78 \mathrm{MPa}$ and density $\sim 1.2 \mathrm{~g} / \mathrm{cm}^{3}$, is selected.

\subsection{Magnetic materials}

The rapid quenched $\mathrm{Nd}_{11.7}(\mathrm{Fe}, \mathrm{Co})_{80} \mathrm{~B}_{8.3}$ magnetic powder obtained by melt spinning method with particle size from 74 to $177 \mu \mathrm{m}$ is employed as a magnetic filler for polymer composite 
magnets manufacturing. Hybrid magnetic composites are produced by replacing the part of $\mathrm{Nd}-(\mathrm{Fe}, \mathrm{Co})-\mathrm{B}$ particles with spherical barium ferrite $\left(\mathrm{BaFe}_{12} \mathrm{O}_{19}\right)$ agglomerates. The magnetic properties of started magnetic materials are presented in Table 1.

\begin{tabular}{|c|c||c|c|c|c|}
\hline \hline Material & Chemical Formula & $\begin{array}{c}B_{r} \\
{[\mathrm{kG}]}\end{array}$ & $\begin{array}{c}H_{\mathrm{cb}} \\
{[\mathrm{kOe}]}\end{array}$ & $\begin{array}{c}H_{\mathrm{cj}} \\
{[\mathrm{kOe}]}\end{array}$ & $\begin{array}{c}(\mathrm{BH})_{\max } \\
{[\mathrm{MGO}]}\end{array}$ \\
\hline \hline Neodymium Iron Boron & $\mathrm{Nd}_{11.7}(\mathrm{Fe}, \mathrm{Co})_{80} \mathrm{~B}_{8.3}$ & 8.2 & 6.0 & 8.7 & 13.1 \\
\hline Barium Ferrite & $\mathrm{BaFe}_{12} \mathrm{O}_{19}$ & 2.3 & 1.9 & 3.6 & 1.3 \\
\hline \hline
\end{tabular}

Table 1. Magnetic properties of started magnetic materials

The chemical composition of the starting Nd-Fe-B alloy is Nd: $21-25 w t \%$, Co: $3-5 w t \%$, B $<1.5$ wt $\%$, Zr: 3-5 wt \%, Fe: balance.

\subsection{Measurements}

The structure and morphology of fracture surfaces of synthesized composite materials are observed by JEOL JSM-5800 Scanning Electron Microscope (SEM), with an accelerating voltage of $20 \mathrm{kV}$. After tensile tests at room temperature, fracture sample surfaces are sputtered with gold using a POLARON SC 502 sputter coater for enhanced conductivity.

Thermal analysis of investigated magnetic composites, as well as pure epoxy material are performed by SDT Q600, TA Instruments equipment for simultaneous DSC/DTA/TGA measurements. The samples are heated at a rate of $5^{\circ} \mathrm{C} / \mathrm{min}$ in a nitrogen environment with a temperature range of ambient temperature up to $600{ }^{\circ} \mathrm{C}$.

A TA Instruments DMA Q800 is used to obtain dynamic mechanical data of investigated magnetic composites and pure epoxy sample. Storage modulus, loss modulus, and tan delta are recorded as a function of temperature. The samples are tested using three-point bend clamp with a $20 \mathrm{~mm}$ span width and rectangular-edge probe, at a frequency of $1 \mathrm{~Hz}$ and displacement amplitude of $20 \mu \mathrm{m}$. A displacement control mode is used to maintain deflection through glass transition temperature $T g$; a Force Track setting of $125 \%$ is used, i.e. an applied static force was $25 \%$ higher than the dynamic force. Samples are placed on a platform located on top of the three-point bend fixture so that no sample deflection could occur during annealing. Testing is done over a temperature range from $25^{\circ} \mathrm{C}$ to $100{ }^{\circ} \mathrm{C}$ with a temperature ramp of $3^{\circ} \mathrm{C} / \mathrm{min}$.

The Nd-Fe-B/epoxy composites and pure epoxy polymer samples are machined into tensile and flexural specimens, which are then tested at ambient temperature. The tensile specimen is dumbbell shaped, as required by ASTM D 3039-00 (American Society for Testing and Materials [ASTM], 2000), with a cross-section of $40 \times 5 \mathrm{~mm}$ in the gauge length. The specimens for flexural tests are rectangular plates $100 \times 10 \times 2 \mathrm{~mm}$ as required by ASTM D 790-03 (ASTM, 2003). At least five specimens are tested in tests consisting of both composite and pure epoxy specimen. The dumbbell-shaped tensile specimens of pure epoxy resin are fabricated by casting the resin into the rubber moulds and following the recommended curing cycle from the material manufacturer. Flexural tests are performed using three point bend kit. A universal material testing machine (Schenck TREBEL RM 100) is used for mechanical tests. The moduli of elasticity are derived from the linear portion of the stressstrain curves obtained by both tensile and flexural tests.

The examination of macroscopic magnetic properties is tested using Superconducting Quantum Interference Device (SQUID) magnetometer. During the measurements at ambient temperature $(300 \mathrm{~K})$, magnetic field strength $\mu_{0} H$ is varied from -5 to $5 \mathrm{~T}$. Sample preparation 
and experimental procedures have been conditioned such that the demagnetization factor can be neglected. While the SQUID magnetometer is a very sensitive device, a magnetic field strength from $10^{-12}$ up to $10^{3} \mathrm{~A} / \mathrm{m}^{2}$ can be measured with accuracy of $0.1 \%$.

\section{Nd-Fe-B / epoxy composite magnetic materials - bonded magnets}

The Nd-Fe-B bonded magnets have been commonly used in various fields, such as electric appliances, automobile parts (Brown et al., 2002; Li et al., 2006), sensing elements (Radojević et al., 2007), electronic, communication and micro-electro-mechanical system (MEMS) applications (Chin, 2000; Hono \& Ping, 2001). Advantages of the using bonded composite materials include their simple technology, possibility of forming their final properties, lowering manufacturing costs because of no costly finishing and lowering of material losses resulting from the possibility of forming any shape (Dobrzanski et al. 2007). The amount of $\mathrm{Nd}-\mathrm{Fe}-\mathrm{B}$ powder in the bonded magnet plays a crucial role in determining magnetic properties. A higher content of Nd-Fe-B powder usually results in a higher remanence magnetization $(\mathrm{Br})$ and maximum energy product $(\mathrm{BH})_{\max }$ and therefore, it is desirable from the magnetic perspectives. However, a higher content of magnetic filler may change the rheology of polymer melt during the process, subsequently, impact the mechanical strength of bonded magnets. Nevertheless, the balance between magnetic properties and corresponding dynamic mechanical behaviour is an important issue for bonded magnet applications (Garrell et al., 2003b). The presented study is undertaken with the intention to understand the effect of different filler contents on the thermal, dynamic mechanical and magnetic properties of the Nd-Fe-B/epoxy magnetic composite materials.

\subsection{Structure and morphology}

Uniform particle distribution and good adhesion between Nd-Fe-B particles and a polymer matrix are essential for the quality of composites, especially at temperatures above the glass transition temperature $(\mathrm{Tg})$ of the polymer. The particle size of magnetic powder plays an important role in determining powder to binder ratio, degree of particle alignment and, magnetic and mechanical properties (Kokabi et al., 2005). Generally speaking, the plate-like particles would result in higher packing density under the optimal compression conditions (Rodrigues et al., 1996; Zhang et al., 2009). SEM micrographs of fracture surface morphology of Nd-Fe-B/epoxy composites are presented in Fig.1.
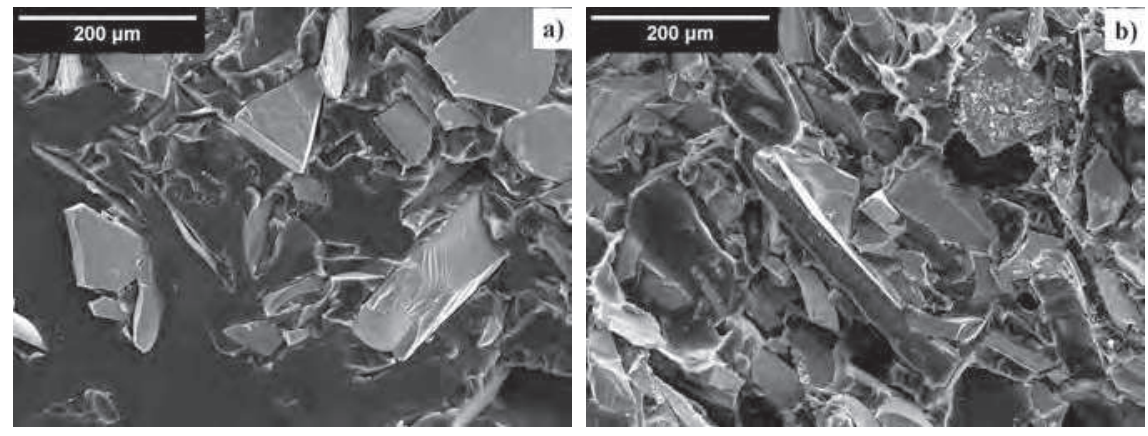

Fig. 1. SEM micrographs of fracture surface of composite material with a) $50 \mathrm{wt} \%$ and b) 95 wt $\%$ of Nd-Fe-B filler observed by JEOL JSM-5800 Scanning Electron Microscope 
The Nd-Fe-B particles are shown as light grey and the epoxy matrix is shown as dark. The darkest gray parts represent the holes ensued by dragging the $\mathrm{Nd}-\mathrm{Fe}-\mathrm{B}$ particles during the mechanical breaking (tension). Although Nd-Fe-B particles are of variable size and shape, they seem to be attached rather well to the matrix.

\subsection{Thermal properties}

Using thermogravimetric analysis (TGA) and differential scanning calorimetry (DSC), different phase transformations caused by decomposition, oxidation, dehydration, etc. can be detected. Also, materials can be analysed in different experimental environments. Increasing the heating rate temperature of transformation can be moved to higher values because a temperature lag between the heater and the specimen occurs (Withaeger, 2001).

The DSC and TG curves for Nd-Fe-B/epoxy composite are shown in Fig. 2. Thermogravimetric experiments (Fig. 2a) were carried out to determine the degradation temperatures $\left(T_{d}\right)$ of magnetic composite materials i.e. the temperature corresponding to the highest rate of weight loss. The results of thermal degradation studies clearly show that the samples with higher amounts of magnetic filler have a lower temperature of thermal degradation and a lower degradation rate in regard to the pure epoxy resin. The results obtained by DSC are in accordance with TG measurements.

DSC curves show an exothermal effect which appears between $300{ }^{\circ} \mathrm{C}$ and $380{ }^{\circ} \mathrm{C}$ refers to the reaction of thermal degradation or decomposition of the composite materials. The change of enthalpy which occurred during this process is decreased with a decrease in the amount of epoxy matrix in the composites. Small endothermic effects in temperature range between $47{ }^{\circ} \mathrm{C}$ and $50{ }^{\circ} \mathrm{C}$ are referring to glass transitions in the investigated composite materials (Maity et al., 2007). The quantitative values of degradation temperatures and the corresponding changes in enthalpy are presented in Table 2.
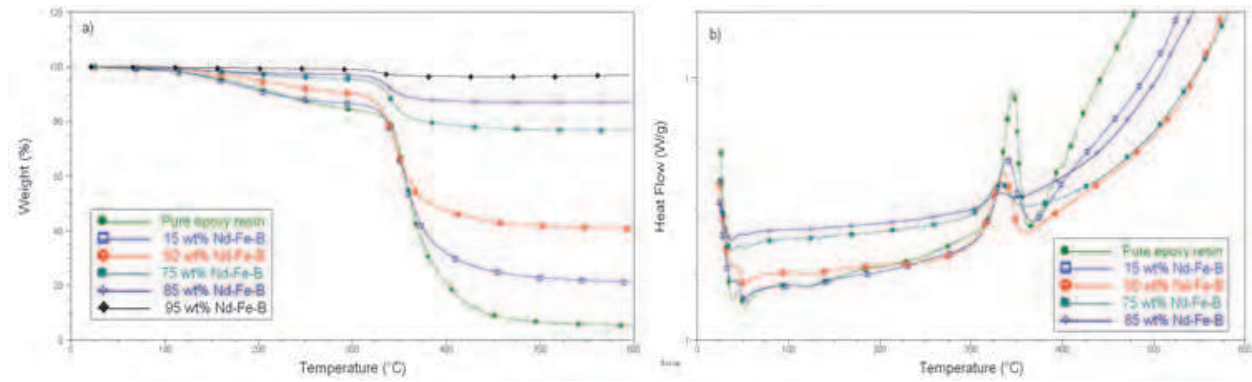

Fig. 2. TG and DSC curves for the pure epoxy resin and Nd-Fe-B composites

The quantitative values of glass transition temperatures $\mathrm{Tg}$ obtained by DSC are presented with DMA results in section 3.3 (Table 3.). Due to negligible thermal effects i.e. enthalpy change, for the sample with $95 \mathrm{wt} \% \mathrm{Nd}-\mathrm{Fe}-\mathrm{B}$, the corresponding DSC curve is not included in the Fig. 2b. All investigated samples have very close values of glass transition temperatures which is confirmed by DMA measurements (Fig. 3). 


\begin{tabular}{|c|c|c|c|}
\hline \multirow{2}{*}{$\begin{array}{c}\text { Sample } \\
\text { (Composite) }\end{array}$} & TG & \multicolumn{2}{|c|}{ DSC } \\
\hline & $\mathrm{Td},{ }^{\circ} \mathrm{C}$ & $\mathrm{Td},{ }^{\circ} \mathrm{C}$ & $\Delta H, \mathrm{~J} / \mathrm{g}$ \\
\hline Pure epoxy resin & 354.7 & 344.6 & 267.8 \\
\hline 15 wt $\%$ Nd-Fe-B & 352.5 & 338.8 & 180.1 \\
\hline $50 w^{t} \%$ Nd-Fe-B & 349.7 & 333.5 & 156.3 \\
\hline 75 wt $\%$ Nd-Fe-B & 342.2 & 330.3 & 72.4 \\
\hline $85 \mathrm{wt} \% \mathrm{Nd}-\mathrm{Fe}-\mathrm{B}$ & 341.3 & 329.2 & 18.9 \\
\hline 95 wt $\%$ Nd-Fe-B & 324.4 & & \\
\hline
\end{tabular}

Table 2. Degradation temperatures and corresponding change of enthalpy obtained from TG and DSC curves

\subsection{Dynamic mechanical properties}

Dynamic mechanical analysis (DMA) is probably the most sensitive single technique available for characterizing and interpreting the mechanical and curing behaviour of polymers and polymer composites. This sensitivity allows the DMA to detect the glass transition temperature, $\mathrm{Tg}$ of highly crosslinked thermosetting polymers or of thin coatings. (Menard, 1999). DMA can be simply described as applying an oscillating force to a sample and analyzing the material's response to that force. The technique separates the viscoelasticity of a material into the two components of complex modulus $\left(E^{*}\right)$, a real part which is the elastic modulus $(E)$ and an imaginary part which is the damping or viscous component $\left(E^{\prime}\right)$, and is expressed $E^{*}=E^{\prime}+i E^{\prime \prime}$ (Ferry, 1980). These properties are often described as the ability to lose energy as heat (damping) and the ability to recover from deformation (elasticity). Due to the viscoelastic nature of polymer composites, their dynamic and thermal behaviour significantly depends on strain, frequency and temperature. For composite materials, particle shape and size, uniform particle distribution, and good adhesion between Nd-Fe-B and polymer, are important parameters which have significant impact on microstructure and stiffness of the final magnetic material (Guschl et al., 2002).

The dynamic mechanical properties of the pure epoxy polymer and the $\mathrm{Nd}-\mathrm{Fe}-\mathrm{B} / \mathrm{epoxy}$ magnetic composite materials are examined as a function of temperature, from the glassy to the rubbery state. Applied three-point bending oscillatory testing is considered as a "pure" mode of deformation and is recommended for stiff materials. The results presented in Fig. 3 show a considerable improvement in the storage modulus (elastic component) caused by the presence of the Nd-Fe-B magnetic filler.
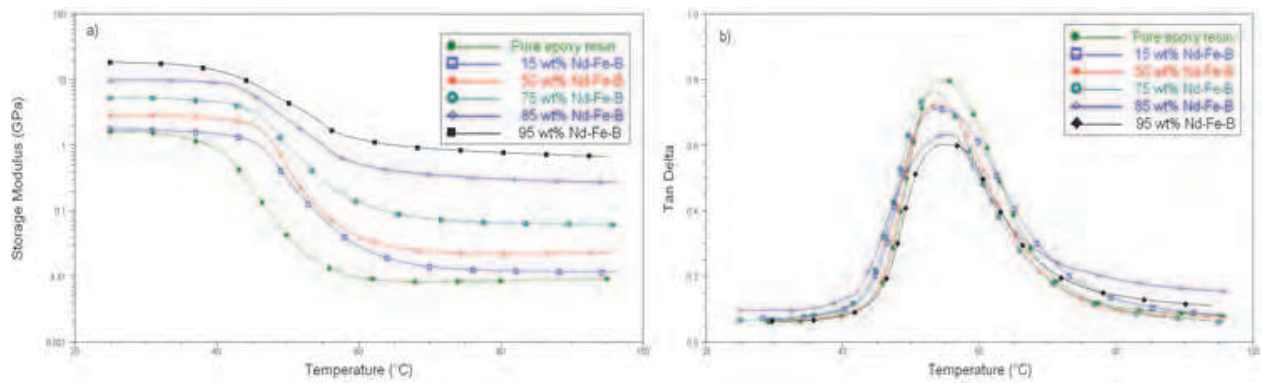

Fig. 3. DMA curves of storage modulus E'and Tand, for the pure epoxy resin and the composites with different $\mathrm{Nd}-\mathrm{Fe}-\mathrm{B}$ filler content versus temperature 
In the glassy region (around $25^{\circ} \mathrm{C}$ ), modulus of the pure polymer, modulus of the filler, and concentrations of both, as well as the adhesion factor between the filler and polymer, have direct influence on the total dynamic modulus of composites (Payne, 1965; Wang, 1999; Alves et al., 2004). The addition of $15 \mathrm{wt} \%$ and $50 \mathrm{wt} \% \mathrm{Nd}-\mathrm{Fe}-\mathrm{B}$ powder into epoxy matrix induce an increase of roughly $6 \%$ and $75 \%$ in the storage modulus of pure epoxy polymer, respectively. Thus, magnetic composites with $75 \mathrm{wt} \%$ and $85 \mathrm{wt} \%$ of magnetic filler were found to have 3.2 and 5.8 times higher storage modulus than the pure epoxy sample, respectively. At the other end of temperature range, the storage modulus decreases with the temperature to the lower values in the rubbery state (Deng et al., 2007). In this region, approximately above $75^{\circ} \mathrm{C}$, the dynamic storage modulus is a function of the hydrodynamic effect, well-known to be dependent on the shape of the filler particles or agglomerates, on the concentration of the filler, and on the fillers interactions with polymer. Comparing to pure epoxy sample values for storage modulus these are 1.7, 2.9, 9.1 and 40 times higher for composites with $15 \mathrm{wt} \%, 50 \mathrm{wt} \%, 75 \mathrm{wt} \%$ and $85 \mathrm{wt} \%$ of Nd-Fe-B, respectively, which is a significant improvement of storage modulus (Grujić et al., 2010a). DMA tests for highly filled Nd-Fe-B/epoxy polymer composite (95 wt $\%$ of Nd-Fe-B) showed an 11 times higher storage modulus values at ambient temperature and up to 87 times higher at $75{ }^{\circ} \mathrm{C}$ (in rubbery state), compared with the polymer matrix. The significant enhancement of the storage modulus in the rubbery region could be explained by the variable size and shape of $\mathrm{Nd}-\mathrm{Fe}-\mathrm{B}$ particles resulting in higher packing density, good particle to particle interaction and attachment to the epoxy matrix (Payne, 1965). When comparing material properties, a material with a higher storage modulus would be stiffer and harder to deform than one with a lower $E^{\prime}$. Besides the elastic component, a material also has a viscous component called the loss modulus $\left(E^{\prime}\right)$. This viscous component relates to the materials ability to lose energy. The material's $\tan \delta$ designates the material's ratio of viscous to elastic components ( $\left.E^{\prime \prime} / E\right)$ and it is sometimes called the materials damping ability (Menard, 1999). A composite material with a higher $\tan \delta(\approx 0.7$ for composite with $15 \mathrm{wt} \%$ of Nd-Fe-B filler) has a higher viscous percentage than one with a lower $\tan \delta(\approx 0.6$ for composite with $95 \mathrm{wt} \%$ of $\mathrm{Nd}-\mathrm{Fe}-\mathrm{B}$ filler). Therefore the material would be more likely to absorb a vibration or impact, and disperse it throughout the material without failure. DMA results presented in Fig. $3 b$ show that glass transition temperatures $(\mathrm{Tg})$ obtained from $\tan \delta$ curves for all investigated magnetic composites were found to lay in the same temperature region (around $54{ }^{\circ} \mathrm{C}$ ). This could be a consequence of the use of Nd-Fe-B powders with similar particle size distribution and without particle surface modification (uncoated) (Otaigbe et al., 1999). The quantitative values of glass transition temperatures obtained by different methods are presented in Table 3.

\begin{tabular}{|c|c|c|c|c|c|c|c|}
\hline \multirow{3}{*}{$\begin{array}{r}\text { Sample } \\
\text { (Composite) }\end{array}$} & \multicolumn{7}{|c|}{ Glass Transition Temperature $\left(T_{g}\right),\left[{ }^{\circ} \mathrm{C}\right]$} \\
\hline & \multicolumn{3}{|c|}{ DSC } & \multirow{2}{*}{$\begin{array}{l}\text { DMA } \\
(\tan \delta)\end{array}$} & \multicolumn{3}{|c|}{ DMA $\left(E^{\prime}\right)$} \\
\hline & onset & midpoint & offset & & onset & midpoint & offset \\
\hline Pure epoxy resin & 46.8 & 48.3 & 50.6 & 54.5 & 39.4 & 43.7 & 48.0 \\
\hline 15 wt $\%$ Nd-Fe-B & 45.3 & 47.2 & 49.8 & 53.9 & 43.4 & 47.1 & 50.8 \\
\hline $50 w t^{\%} \%$ Nd-Fe-B & 44.4 & 47.0 & 49.3 & 53.8 & 43.8 & 47.6 & 50.5 \\
\hline 75 wt $\%$ Nd-Fe-B & 46.7 & 48.4 & 50.2 & 53.3 & 40.7 & 46.9 & 51.6 \\
\hline 85 wt $\%$ Nd-Fe-B & 47.0 & 49.1 & 51.1 & 55.0 & 41.8 & 45.6 & 51.2 \\
\hline 95 wt $\%$ Nd-Fe-B & & & & 55.3 & 39.4 & 45.0 & 52.2 \\
\hline
\end{tabular}

Table 3. Glass transition temperatures obtained by DSC and DMA 
The difference in $\mathrm{Tg}$ value for each composite obtained from DSC and DMA arises due to the difference in the method of measurement and the variations in the definition of transition temperature used (Maity et al., 2007).

\subsection{Tensile and flexural properties}

In order to determine the in-plane tensile and flexural properties of the polymer matrix composite materials reinforced by the $\mathrm{Nd}-\mathrm{Fe}-\mathrm{B}$ magnetic particles, standard test tensile and flexural methods are used (ASTM, 2000, 2003). The ultimate tensile stress $\sigma_{m}$ of the investigated magnetic composite materials is calculated using:

$$
\sigma_{m}=\frac{F_{\max }}{b \cdot d}
$$

Where: $\sigma_{m}$ - ultimate tensile stress, MPa; $F_{\max }$ - maximal load before failure, $\mathrm{N} ; b$ - sample width, $\mathrm{mm}$; and $d$ - sample thickness, $\mathrm{mm}$.

The values of ultimate tensile stress, elongation and modulus of elasticity have been taken from obtained stress-strain diagrams for all investigated composites, and presented as a function of the Nd-Fe-B content in the epoxy matrix respectively (Fig.4. \& Fig.6.). The elastic modulus $E$ of investigated magnetic composite materials was calculated using:

$$
E=\frac{\Delta \sigma}{\Delta \varepsilon}=\frac{\Delta F}{\Delta \varepsilon} \cdot \frac{1}{b \cdot d}
$$

Where the ratio $\Delta \sigma / \Delta \varepsilon$ is determined by linear regression method. From the linear portion of stress-strain curves i.e. in the Hookean region.

With a decreasing quantity of the thermosetting epoxy polymer in the composites i.e. with an increasing content of the Nd-Fe-B filler, the values of tensile stress and elongation are decreasing (Fig. 4.). In addition, composite materials become more brittle, and less ductile (Hemrick et al., 2004; Grujić et al., 2010b).
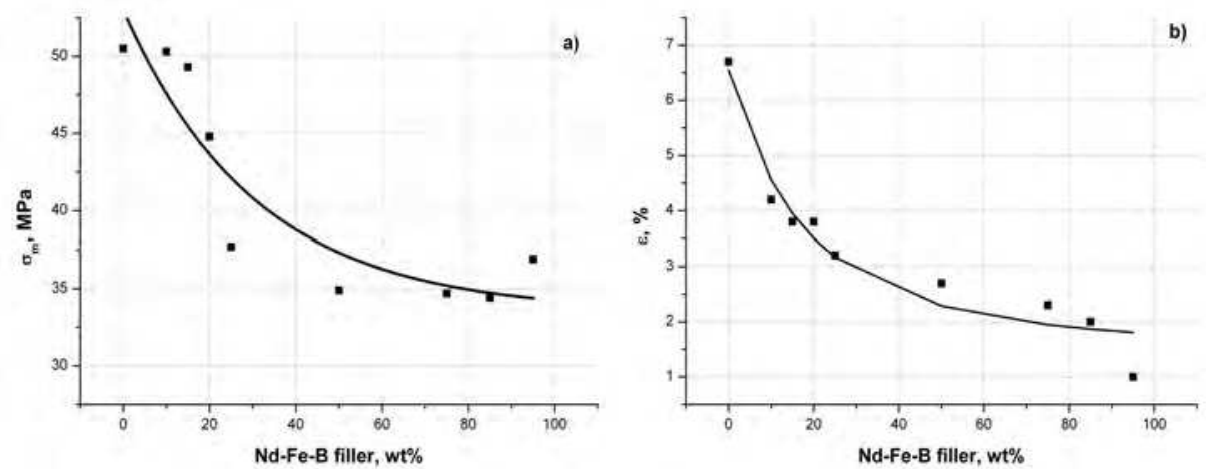

Fig. 4. a) Ultimate tensile stress, and b) strain in function of $\mathrm{Nd}-\mathrm{Fe}-\mathrm{B}$ content

The test methods according to ASTM D 790-03 (ASTM, 2003) cover the determination of flexural properties of unreinforced and reinforced plastic materials, including high-modulus composites. These test methods are generally applicable to both rigid and semi-rigid materials. However, flexural strength cannot be determined for those materials that do not 
break or that do not fail in the outer surface of the test specimen within a $5.0 \%$ strain limit of these test methods. When a homogeneous elastic material is tested in flexure as a simple beam supported at two points and loaded at the midpoint, the maximum stress in the outer surface of the test specimen occurs at the midpoint. This stress may be calculated for any point on the load-deflection curve by means of the following equation:

$$
\sigma_{f}=\frac{3 F \cdot L}{2 b \cdot d^{2}}
$$

where: $\sigma_{f}$ - stress in the outer surface at midpoint, MPa; F - load at a given point on the load-deflection curve, $\mathrm{N}$; L - support span, $\mathrm{mm} ; b$ - width of beam tested, $\mathrm{mm}$, and $d$ - depth of beam tested, $\mathrm{mm}$.

Deformation caused by flexural test $\varepsilon_{f}$ is fractional change in the length of an element of the outer surface of specimen at middle point, where stress is maximal, and it can be calculated using the following equation:

$$
\varepsilon_{f}=\frac{6 D \cdot d}{L^{2}}
$$

where: $\varepsilon_{f}$ - strain at outer (opposite) surface, $\mathrm{mm} / \mathrm{mm}$; $D$ - maximal deflection in middle point of specimen, $\mathrm{mm}, L$-support span, $\mathrm{mm}$; and $d$ - thickness of the specimen, $\mathrm{mm}$.

The tangent flexural modulus of elasticity represents the ratio of stress to corresponding strain in the range of elastic behaviour of materials. The flexural modulus of elasticity is calculated by drawing a tangent to the steepest initial straight-line portion of the load deflection curve. Similar to tensile test results, the flexural stress and elongation are decrease with increasing content of Nd-Fe-B filler (Fig. 5).
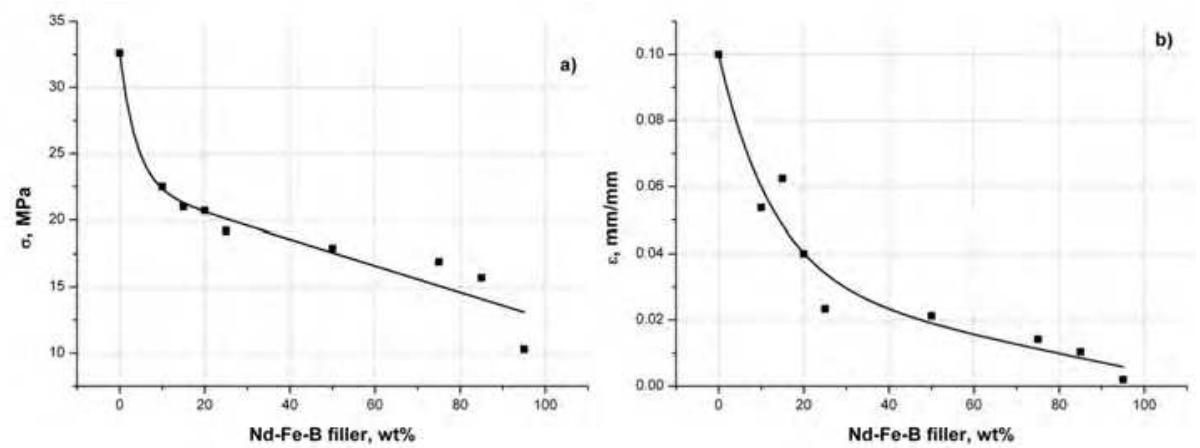

Fig. 5. Ultimate flexural stress and strain as the function of Nd-Fe-B content

Moduli of elasticity obtained by both tensile and flexural tests are increase with higher quantities of magnetic filler. This is crucial in analysis of possible use of the investigated magnetic composite materials as functional material (Fig. 6.). This means that material with higher amounts of Nd-Fe-B filler, subject to equal stress levels (ballast), tolerate 2 to 3.5 times lower deformation.

The modulus of elasticity is a very important parameter for analysis of the composite materials behaviour under discontinuous load conditions. The values of elastic modulus, 
obtained by tensile and flexural tests, upswing with an increasing amount of Nd-Fe-B powder from $50 \mathrm{wt} \%$ achieve 9.2 and $7.1 \mathrm{GPa}$, respectively. Within the narrow region, up to $20 \mathrm{wt} \%$ content of $\mathrm{Nd}-\mathrm{Fe}-\mathrm{B}$, where the modulus of elasticity is practically constant according to tensile and flexural tests, dynamic-mechanical analysis could be applied to acquire additional information's related to mechanical behaviour about transitions in polymer composites (Maity et al., 2007; Almagableh et al., 2008).

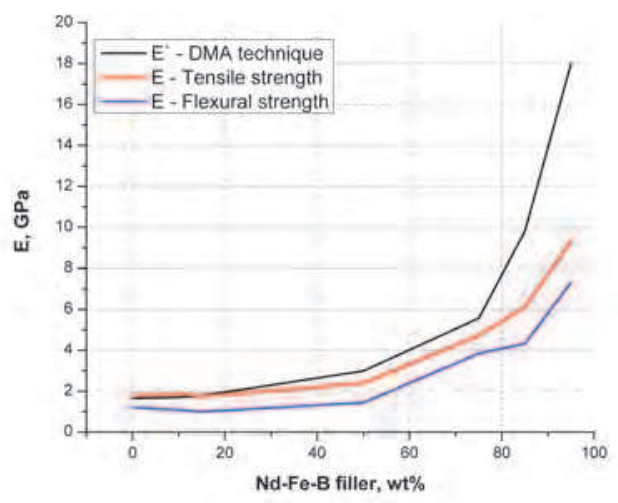

Fig. 6. Comparative view of the changes in the modulus of elasticity at $25^{\circ} \mathrm{C}$

The values of storage modulus observed by DMA were compared with elastic modulus obtained by tensile and flexural tests (Fig. 6.). In contrast to Deng, S. et al. (Deng et al., 2007) mechanical properties at temperatures higher than ambient are not compared with DMA results observed using two different clamps. It seems that observing the elastic modulus of composites by tensile, flexural and DMA tests at room temperature in the present study gives a better look at the increasing trend of elastic component of materials with increasing $\mathrm{Nd}-\mathrm{Fe}-\mathrm{B}$ filler content in the polymer matrix.

\subsection{Mathematical prediction of Nd-Fe-B / epoxy composite behaviour}

The strong influence of relatively small amounts of filler particles on the dynamic mechanical properties of polymers has significantly contributed to increased use of polymer materials in many commercial applications (Bergstrom \& Boyce, 1999). The incorporation of filler particles is known to increase the stiffness of the material and alter time dependent aspects of material behaviour such as hysteresis and stress relaxation. Even at strains sufficiently large for the structure to have been eliminated, the storage modulus is greater than that of the pure polymer and, greater than the amount which can be predicted due to hydrodynamic interaction of the filler particles.

Ideally, in an attempt to reduce laboratory cost, one would like to make a prediction of a new material's behaviour by numerical simulation, with the primary goal being to accelerate trial and error experimental testing. The recent dramatic increase in computational power available for mathematical modelling and simulation raises the possibility that modern numerical methods can play a significant role in the analysis of heterogeneous microstructures. This section is devoted to the mathematical prediction of storage modulus of observed composite. The focus is on analytical models, due to fact that they are simple to use and required input data are only properties of individual constituents of composite and 
their fraction. The several proposed analytical models are tested versus experimental data as it is illustrated in following text. Some of applied models agree very well with experimental data, whilst others deviate significantly.

There have been several attempts to derive formulas giving the apparent modulus due to a dispersion of particles in polymer (Donnet, 1998). The earliest of these attempts was by Smallwood using the analogy to Einstain's viscosity equation:

$$
E_{\text {comp }}=E_{\text {matrix }}(1+2.5 c)
$$

where: $E_{\text {comp }}$ - storage modulus of composite $(\mathrm{Pa}), E_{\text {matrix }}$ - storage modulus of matrix $(\mathrm{Pa})$, and $c$ - volume faction of particle in composite

Smallwood's estimate is only good at very low filler concentrations. A number of attempts have been made to incorporate interactions between neighbouring particles to allow prediction at higher volume fractions. Most of these models add one or more terms to a polynomial series expansion. One of the most cited model of this class is the Guth-Gold (Guth \& Gold, 1938):

$$
E_{\text {comp }}=E_{\text {matrix }}\left(1+2.5 c+14.1 c^{2}\right)
$$

Later Guth extended the Guth-Gold model to include impact of particle shape on properties. Guth introduced a shape factor $\mathrm{f}$ (ratio of diameter to width of particle) and proposed a new equation (Guth, 1945):

$$
E_{\text {comp }}=E_{\text {matrix }}\left(1+0.67 f \cdot c+1.62 f^{2} \cdot c^{2}\right)
$$

Budiansky developed a model, for the special case of rigid particles in an incompressible matrix written as (Budiansky, 1965):

$$
E_{\text {comp }}=\frac{E_{\text {matrix }}}{1-2.5 c}
$$

Ponte Castaneda has proposed a different self-consistent estimate for rigid particles in a neoHookean matrix (Ponte Castaneda, 1989):

$$
E_{\text {comp }}=\frac{E_{\text {matrix }}}{1-3 c}
$$

Later Govindjee and Simo proposed the novel model, for the case of rigid particles in a neoHookean matrix written (Govindjee \& Simo, 1991):

$$
E_{\text {comp }}=E_{\text {matrix }} \frac{1-c / 2}{1-c}
$$

In addition, it is worth to mention the empirical formula suggested by Brinkmann (Brinkman, 1952):

$$
E_{\text {comp }}=E_{\text {matrix }}(1-c)^{-\frac{5}{2}}
$$


Major characteristics of all aforementioned theoretical models are: they neglect the impact of filler properties and assume that the medium wets the filler particles, but they do not chemically react with the filler surface. Mori-Tanaka proposed a model, which takes into consideration the impact of filler properties on overall composite properties (Mori \& Tanaka, 1973). The Mori-Tanaka model for spherical particles isotropically dispersed in an elastic matrix can be written as:

$$
\begin{gathered}
K_{\text {comp }}=K_{\text {matrix }}+\frac{c\left(K_{\text {particle }}-K_{\text {matrix }}\right) K_{\text {matrix }}}{\frac{3 K_{\text {matrix }}(1-c)\left(K_{\text {particle }}-K_{\text {matrix }}\right)}{3 K_{\text {matrix }}+4 G_{\text {matrix }}}+K_{\text {matrix }}} \\
G_{\text {comp }}=G_{\text {matrix }}+\frac{c\left(G_{\text {particle }}-G_{\text {matrix }}\right) G_{\text {matrix }}}{(1-c)\left(G_{\text {particle }}-G_{\text {matrix }}\right) \frac{6\left(K_{\text {matrix }}+2 G_{\text {matrix }}\right)}{5\left(3 K_{\text {matrix }}+4 G_{\text {matrix }}\right)}+G_{\text {matrix }}} \\
E_{\text {comp }}=\frac{9 K_{\text {comp }} G_{\text {comp }}}{3 K_{\text {comp }}+G_{\text {comp }}}
\end{gathered}
$$

where: $K_{\text {comp }}, K_{\text {matrix }}, K_{\text {particle }}$ are bulk modulus of composite, matrix and particle, respectively $(\mathrm{Pa})$, and $G_{\text {comp }}, G_{\text {matrix }}, G_{\text {particle }}$ are shear modulus of composite, matrix and particle, respectively.

The experimentally obtained values of storage modulus are compared with analytical models discussed above and presented in Fig. 7. Predictions of models proposed by Budiansky, Ponte Castaneda and Govindjee-Simo give inadequate estimation so they are not included in Fig. 7.

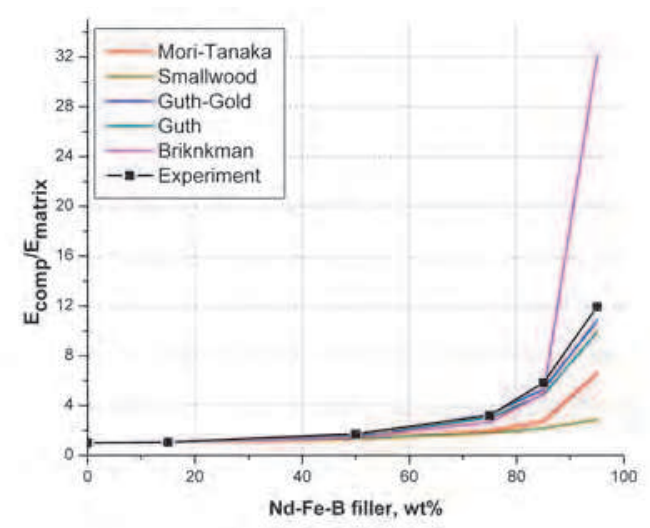

Fig. 7. Models predictions against experimental data

From Fig. 7 one may notice that all models included in analysis give very good predictions of storage modulus at lower particles concentrations (till 50\%). This suggests that in this concentration range, the interactions between neighbouring particles have very low 
intensity. At higher concentrations, interactions become high intensity, this is why the Smallwood's model starts to show significant deviation from experimental results. MoriTanaka's model follows the trend of experimental results, but it gives poor predictions. Brinkman's model gives good predictions at high concentrations, but at very high concentrations of particles, it extensively overpredicts the storage modulus. The Guth and Guth-Gold models are in very good agreement with experimental results. The explanation for this behaviour lies in the fact that both models take into consideration interactions between neighbouring particles.

\subsection{Magnetic properties}

Characteristic of all magnetic materials is a manifestation of the hysteresis phenomena. The hard magnetic materials have the greater values of hysteresis (Goll \& Kronmüller, 2000). A word of Greek derivation, hysteresis describes magnetic materials as highly nonlinear, meaning that their response to a stimulus lags behind in a repeatable manner. The stimulus in this case is an applied magnetic field and the material's response is the magnetization or induction (Trout, 2000). Magnetic properties of magnetic composite materials (bonded magnets) are affected by the magnetic properties of the magnetic powder and weight (volume) ratio of the powder. It is known that bonded magnets have inferior magnetic characteristics compared to magnetic material obtained by convectional methods (sintering for example), because in bonded technology maximal density of magnetic powder can not be achieved (Zhang et al., 2009). One of the most important characteristics of the used type of $\mathrm{Nd}-\mathrm{Fe}-\mathrm{B}$ rare-earth magnetic material is high values of remanence and coercivity, which have a direct influence on high values of maximum energy product (Gutfleisch 2000; Chen et al., 2004). The results of magnetic measurements i.e. complete hysteresis loops for bonded $\mathrm{Nd}-\mathrm{Fe}-\mathrm{B} /$ epoxy type magnets with different content of functional magnetic particles are presented in Fig. 8a. It is obvious that the largest hysteresis loop correspond to the magnetic composite with the highest amount of magnetic component.
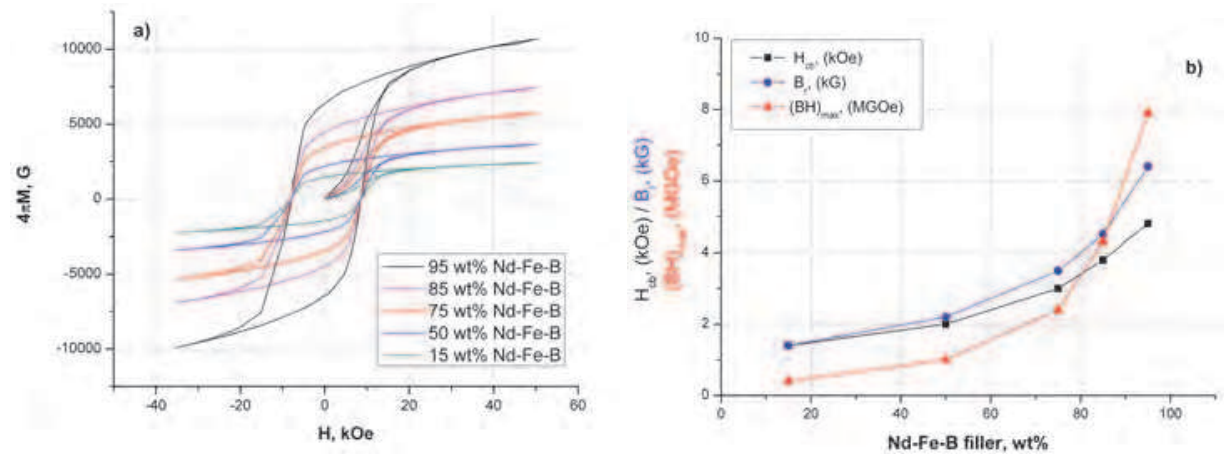

Fig. 8. a) Hysteresis loops of magnetic composites, b) magnetic properties of the composites as the function of the Nd-Fe-B filler content

On the basis of these results corresponded B-H diagrams are constructed and the changes of remanence $(\mathrm{Br})$, coercivity $(\mathrm{Hcb})$ and maximum energy product $\left(\mathrm{BH}_{\max }\right)$ with an increasing content of Nd-Fe-B in the epoxy matrix are taken and presented in Fig. 8b. The presented graph illustrates the upswing of three magnetic parameters of composite materials with increasing amounts of $\mathrm{Nd}-\mathrm{Fe}-\mathrm{B}$ particles in the epoxy matrix. For example, the maximum 
energy product for composite with $95 \mathrm{wt} \% \mathrm{Nd}-\mathrm{Fe}-\mathrm{B}$ is around $8 \mathrm{MGOe}$, which is two times higher than for composite with the $85 \mathrm{wt} \% \mathrm{Nd}-\mathrm{Fe}-\mathrm{B}$ case. For composites with Nd-Fe-B content higher than $75 \mathrm{wt} \%,(B H)_{\max }$ rapidly increase i.e. for the highly filled composites even a small addition of magnetic medium have a strong influence on magnetic properties of bonded magnets. Also, the maximum energy product $(\mathrm{BH})_{\max }$ of $\mathrm{Nd}-\mathrm{Fe}-\mathrm{B}$ bonded magnets can be simulated using a mathematical model, and choosing appropriate parameters for the magnetic texture and the magnetic coupling micro-grains, one can increase the value of $(B H)_{\max }$ (Vuong et al., 2003, Xiao et al., 2000).

\section{Hybrid magnetic materials}

One way of improving some physical properties of the bonded magnets is to produce the hybrid magnets prepared from a mixture of two powders with different properties, e.g. the $\mathrm{Nd}-\mathrm{Fe}-\mathrm{B}$ powders with barium ferrite (Plusa et al., 2006). The addition of ferrite to the $\mathrm{Nd}-$ Fe-B powder decreases the temperature coefficient of coercivity (commonly known as $\beta$ $\left.\left[\% /{ }^{\circ} \mathrm{C}\right]\right)$, which means that this type of bonded magnet can work under elevated temperatures. Also, for example, the bonded magnet has improved the mechanical properties with addition of iron powder (Dobrzanski \& Drak, 2008). Further benefits of adding ferrite or iron would be cost reduction and ease of magnetization.

The synthesized hybrid magnetic composite materials correspond to a mixture of $\mathrm{Nd}-\mathrm{Fe}-\mathrm{B}$ and barium ferrite in different ratio. More precisely, this type of composite can be observed as a substitution of a part of $\mathrm{Nd}-\mathrm{Fe}-\mathrm{B}$ particles with barium ferrite. A better insight into the effect of added barium ferrite to the final characteristics of hybrid composite materials are examined for a constant quantity of the polymer matrix. SEM micrographs of hybrid magnetic composite materials are presented in Fig. 9.
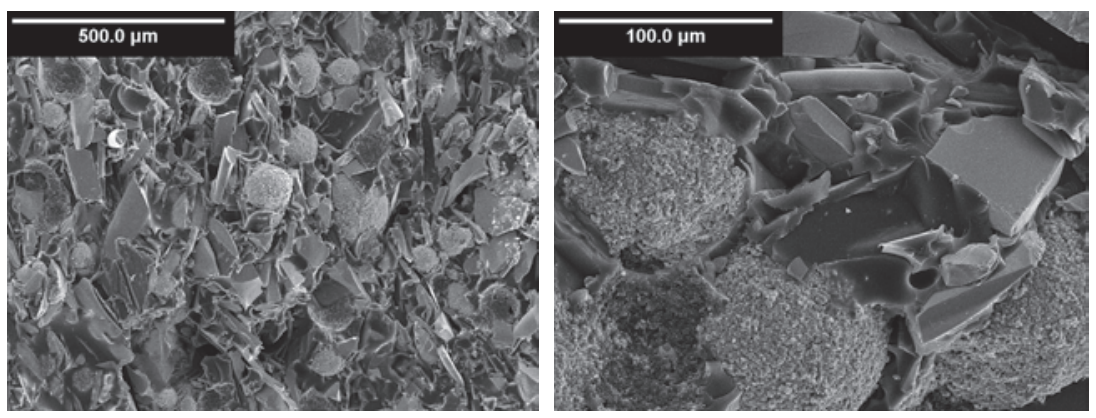

Fig. 9. SEM micrographs of hybrid magnetic composite materials

Since the crumbled ferrite agglomerates are incorporated between bigger particles of ferrite and $\mathrm{Nd}-\mathrm{Fe}-\mathrm{B}$, they contribute to the improved dynamic mechanical properties of composite. The results of DMA are presented in Fig. 10. For different types of composites, the values of storage modulus and tan $\delta$ are compared. All composites have improved storage modulus compared to pure epoxy resin, while the hybrid Nd-Fe-B/barium ferrite/epoxy resin type composite has the highest value (Fig. 10a). The peaks of tan $\delta$ curves lie in a temperature region between $45-50^{\circ} \mathrm{C}$ and indicate glass transition temperatures. 
This phenomenon is continuously investigated using composites with different ratios of magnetic particles and for various types of polymer matrices. For this purpose, injection bonded magnets are produced using thermoplastic poly (methyl methacrylate) (PMMA) as a matrix and $\mathrm{Nd}-\mathrm{Fe}-\mathrm{B}$ and barium ferrite as a functional magnetic component, in order to investigate the dynamic mechanical properties of hybrid composite materials. The results presented in Fig. 11 show the same tendency of increasing the storage modulus as for composites with epoxy matrix. Hybrid magnetic composite has improved elastic properties compared to the pure PMMA matrix, Nd-Fe-B/PMMA and barium ferrite/PMMA composite materials. Tan $\delta$ curves for composites with PMMA matrix (Fig. 11b) show that the glass transition temperature is around $125^{\circ} \mathrm{C}$ and strongly depends on used polymer.
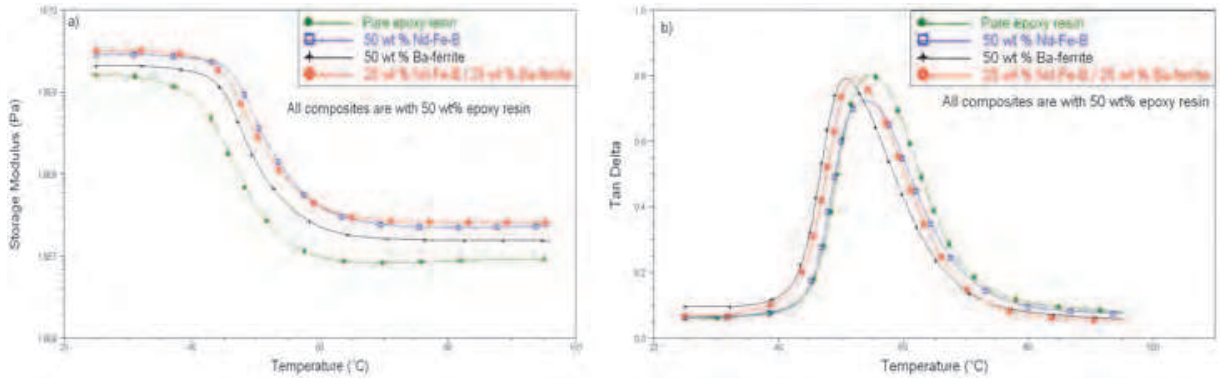

Fig. 10. Nd-Fe-B/epoxy composites: a) storage modulus, and b) $\tan \delta$ as the function of temperature
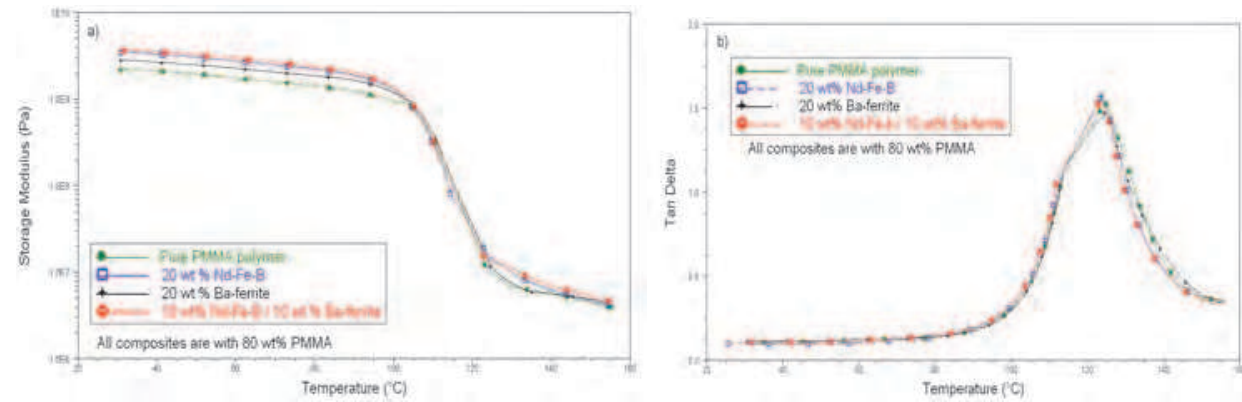

Fig. 11. Nd-Fe-B/PMMA composites: a) storage modulus, and b) $\tan \delta$ as the function of temperature

Magnetic properties of started magnetic powders and hybrid composite materials are investigated and corresponding SQUID hysteresis loops are presented in Fig. 12a. The shape of barium ferrites hysteresis loop illustrates that magnetic saturation $(M s)$ is achieved at 70 $\mathrm{emu} / \mathrm{g}$. The coercivity, remanence and consecutively maximum energy product values are less significant as for Nd-Fe-B powder (Goll \& Kronmüller, 2002). The saturation magnetization Nd-Fe-B alloy is about 3 times higher than barium ferrite. The values presented in Fig. 12a should be taken as approximate because the field strength of SQUID magnetometer $(5 \mathrm{~T})$ is not sufficient for full saturation of $\mathrm{Nd}-\mathrm{Fe}-\mathrm{B}$ powders. It can be seen in the first quadrant, the horizontal end of the hysteresis loop of barium ferrite indicates that this magnetic powder achieves complete saturation, as opposed to Nd-Fe-B alloy. 
It is obvious from Fig. 12a that the hysteresis loops becomes more constricted as the quantity of barium ferrite increases, which is consistent with the investigations of D. Plusa et al. (Plusa et al., 2006). With an increasing content of barium ferrite in the hybrid composites, the value of magnetic remanence, coercive force, and the maximum magnetic energy decreases. Change of magnetic properties, is practically linear in relation to the magnetic powders ratio (Nd-Fe-B to barium ferrite) in hybrid composites. The magnetic properties of hybrid magnetic composites are taken from obtained hysteresis loops and used for constructing the diagram presented on Fig. $12 b$.
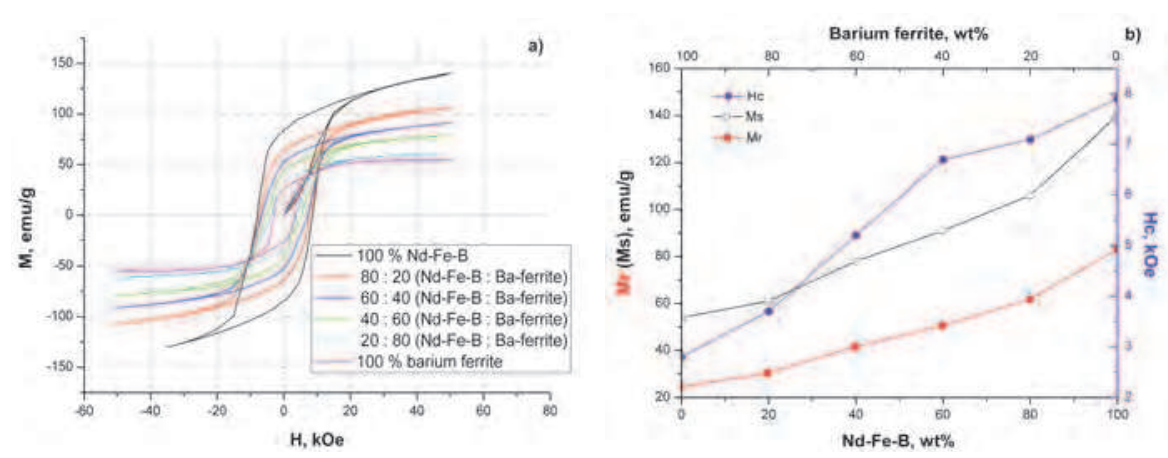

Fig. 12. a) SQUID hysteresis loops of starting magnetic powders and hybrid magnetic materials and b) magnetic properties as the function of $\mathrm{Nd}-\mathrm{Fe}-\mathrm{B}$ and barium ferrite content

\section{Conclusion}

The results of this study show that addition of plate shape Nd-Fe-B particles to the polymer affect the rheological properties the polymer matrix via internal structural changes and, subsequently, the impact the mechanical strength of bonded magnets. Moreover, the stability of composite materials at elevated temperatures is a crucial property has a major impact on their utilization.

There is a wide range of polymers and magnetic powders that may be used for production of magnetic composites. It seems that the mixture of Nd-Fe-B particles and epoxy resin is suitable for bonded magnet applications due to good adhesion, homogeneity, mechanical and magnetic properties. One of the characteristics of this type of materials is that the degradation temperature rises as the content of epoxy increases. The thermal experiments DSC/TGA reveals that the addition of a high quantity of Nd-Fe-B particles results in a reduction of the composite thermal decomposition enthalpy. On the other side, glass transition temperatures evaluated by DSC and DMA disclose that concentration of particles have no impact on glass transition temperature. This result could be a consequence of applied micro size particles without coupling agents or additives. Moreover, DMA data show that the value storage modulus amplifies in glassy, as well as in rubbery state, as the concentration of filler in composite rises. The tensile and flexural tests at ambient temperature show enhancement of modulus of elasticity with quantity of magnetic filler, which is a crucial parameter for analysis of composite materials behaviour. Information extracted from tensile and flexural tests are consistent with results evaluated by DMA. As expected, magnetic properties are drastically improved with higher quantities of Nd-Fe-B magnetic powder, especially for highly filled composites. These results provide information 
about the Nd-Fe-B/epoxy composites which could be of importance in cases where the relatively brittle metallic permanent magnets are not useable.

Hybrid materials development and utilization are economically motivated, due to fact that these materials can be produced at low cost. For example, replacing one fraction of Nd-Fe-B with less expensive barium ferrite creates a new hybrid composite. This hybrid composite shows lower intensity of magnetic property comparing to the original composite, but on the other side shows improved dynamic mechanical properties. In view of aforementioned facts on the subject of hybrid materials, it could be said that hybrid materials could replace existing composite materials in numerous applications.

For better insight into viscoelastic behaviour of composites, beside experiments, a theory that explicitly takes the particle distribution, shape factor, particle-particle interactions as well as particle-polymer matrix interactions into account is required. Considering the increasing interest in polymer composites and advanced analytical tools, the present study provides a useful basis and motivation for future experiments and theory development for the multifunctional components and commercially important polymer bonded magnets.

Further work has been focused on researching and developing bonded $\mathrm{Nd}-\mathrm{Fe}-\mathrm{B}$ composite materials with thermoplastic or rubber matrix using the injection or extrusion methods. Design of the composites with improved dynamic mechanical and optical properties can be realized by assembling magnetic powders and fibres blends. Also, corrosion resistance is one of the potential goals in further research activities.

\section{Acknowledgement}

The authors are grateful to colleagues from the Department for Materials and Metallurgy, ICTM and from the Department for Special Materials TMF, Belgrade for cooperation during research. Also, the authors are indebted to Nada Lazić, Zijah Burzić and Vojislav Spasojević for the measurements and results interpretation. A great appreciation for the assistance with preparation of this chapter authors owe to Ms Sabla Alnouri from TAMUQ. This work has been supported by the Ministry of Science and Technological Development of the Republic of Serbia under Projects: TR 34011 and III 45019.

\section{References}

Almagableh, A.; Gupta, S.; Mantena, P.R \& Al-Ostaz, A. (2008). Dynamic Mechanical Analysis of Graphite Platelet and Nanoclay Reinforced Vinil Ester, and MWCNT Reinforced Nylon 6,6 Nanocomposites, Proceedings of 40th ISTC, Memphis, Tennessee, September, 2008,

Alves, N.M.; Gomez Ribelles J.L.; Gomes Tejedor J.A. \& Mano,J.F. (2004). Viscoelastic Behavior of Poly(methyl methacrylate) Networks with Different Cross-Linking Degrees. Macromolecules, Vol. 37, No. 10, pp. 3735-3744, ISSN 0024-9297

ASTM standard D 3039/D 3039M-00, (2000). Standard Test Method for Tensile Properties of Polymer Matrix Composite Materials, American Society for Testing and Materials

ASTM standard D 790-03, (2003). Standard Test Method for Flexural Properties of Unreinforced and Reinforced Plastics and Electrical Insulating Materials, American Society for Testing and Materials

Bergstrom J.S. \& Boyce, M.C. (1999). Mechanical Behavior of Particle Filled Elastomers. Rubber Chemistry and Technology, Vol. 72, pp. 633-656, ISSN 0035-9475

Brinkman, H.C. (1952). The viscosity of concentrated suspensions and solutions, Journal of Chemical Physics, Vol. 20, No. 4, pp. 571, ISSN 0021-9606 
Brown, D.; Ma, B.M. \& Chen, Z. (2002). Developments in the processing and properties of NdFeB-type permanent magnets. Journal of Magnetism and Magnetic Materials, Vol. 248, No. 3, pp. 432-436, ISSN 0304-8853

Brown, D.N.; Chen Z.; Guschl P. \& Campbell P. (2006). Developments with melt spun REFe-B powder for bonded magnets. Journal of Magnetism and Magnetic Materials, Vol. 303, No. 2, pp. e371-e374, ISSN 0304-8853

Budiansky, B. (1965). On the elastic moduli of some heterogeneous materials. Journal of the Mechanics and Physics of Solids, Vol.13, pp.223-227, ISSN 0022-5096

Chen, Z.; Wu, Y.Q.; Kramer, M.J.; Smith, B.R.; Ma B.M. \& Huang, M.Q. (2004). A study on the role of $\mathrm{Nb}$ in melt-spun nanocrystalline $\mathrm{Nd}-\mathrm{Fe}-\mathrm{B}$ magnets, Journal of Magnetism and Magnetic Materials, Vol. 268, pp. 105-113, ISSN 0304-8853

Chin, T.S. (2000). Permanent magnet films for applications in microelectromechanical systems. Journal of Magnetism and Magnetic Materials, Vol. 209, No. 1-3, pp. 75-79, ISSN 0304-8853

Deng, S.; Hou, M. \& Ye, L. (2007). Temperature-dependent elastic moduli of epoxies measured by DMA and their correlations to mechanical testing data, Polymer Testing, Vol. 26, No. 6, pp. 803-813, ISSN 0142-9418

Dobrzanski, L.A.; Drak, M. \& Ziebowicz, B. (2007). New possibilities of composite materials application-Materials of specific magnetic properties. Journal of Materials Processing Technology, Vol.191, pp. 352-355, ISSN 0924-0136

Dobrzanski, L.A. \& Drak, M. (2008). Hard magnetic composite materials Nd-Fe-B with additions of iron and X2CrNiMo-17-12-2 steel, Journal of Alloys and Compounds, Vol. 449, No. 1-2, pp. 88-92, ISSN 0925-8388.

Donnet, J.P. (1998). Black and White Fillers and Tire Compound, Rubber Chemistry and Technology, Vol. 71, pp. 323-341, ISSN 0035-9475

Ferry, J.D. (1980). Viscoelastic Properties of Polymers (3rd edition), John Wiley \& Sons, Inc., ISBN 0471048941, New York

Garrell, M.G.; Shih, A.J.; Ma, B.M.; Lara-Curzio, E. \& Scattergood, R.O. (2003a). Mechanical properties of Nylon bonded Nd-Fe-B permanent magnets. Journal of Magnetism and Magnetic Materials, Vol. 257, No. 1, pp. 32-43 ISSN 0304-8853

Garrell, M.G.; Ma, B.M.; Shih, A.J.; Lara-Curzio, E. \& Scattergood, R.O. (2003b). Mechanical properties of polyphenylene-sulfide (PPS) bonded Nd-Fe-B permanent magnets. Materials Science and Engineering: A, Vol. 359, pp. 375-383, ISSN 0921-5093

Goll. D. \& Kronmüller, H. (2000). Coercivity Mechanism in a Nanocrystalline and Bonded Magnets, In: Bonded Magnets, Series II: Mathematics, Physics and Chemistry Vol.118, Hadjipanayis, G.C., pp.115-127, Kluwer Academic Publishers, NATO Science Series, ISBN 1-4020-1535-6, Netherlands

Goll. D. \& Kronmüller, H. (2002). High-performance permanent magnets. Naturwissenschaften, Vol. 87, pp. 423-438, ISSN 0028-1042

Govindjee, S. \& Simo, J. C., (1991). A micro-mechanically based continuum damage model for carbon black-filled rubbers incorporating Mullin's effect, Journal of the Mechanics and Physics of Solids, Vol. 39, No. 1, pp. 87-112, ISSN 0022-5096

Gronefeld, M. (2002). Review on Bonded Magnets, In: Bonded Magnets, Series II: Mathematics, Physics and Chemistry - Vol.118, Hadjipanayis, G.C., pp.1-12, Kluwer Academic Publishers, NATO Science Series, ISBN 1-4020-1535-6, Netherlands

Grujić, A.; Lazić, N.L.; Talijan, N.M.; Spasojević, V.; Stajić-Trošić, J., Ćosović, V. \& Aleksić, R. (2010a). Polymer - Bonded Magnetic Materials with Various Nd-Fe-B Filler Content, Acta Physica Polonica A, Vol. 117, No. 5, pp. 859-863, ISSN 0587-4246 
Grujić, A.; Talijan, N.; Stojanović, D.; Stajić-Trošić, J.; Burzić, Z.; Balanović, Lj. \& Aleksić, R. (2010b). Mechanical and Magnetic Properties of Composite Materials with Polymer Matrix. Journal of mining and metallurgy, Section B: Metallurgy, Vol. 46, No. 1, pp. 25-32, ISSN 1450-5339

Guschl, P.C; Kim, H.S. \& Otaigbe, J.U. (2002). Effects of a Nd-Fe-B Magnetic Filler on the Crystallization of Poly(phenylene sulfide). Journal of Applied Polymer Science, Vol. 83, pp. 1091-1102, ISSN 0021-8995

Gutfleisch, O. (2000). Controlling the properties of high energy density permanent magnetic materials by different processing routes. Journal of Physics. D: Applied Physics, Vol. 33, pp. R157-R172, ISSN 0022-3727

Gutfleisch, O.; Willard, M.A.; Brück, E.; Chen, C.H.; Sankar, S.G. \& Liu, J.P. (2011). Magnetic Materials and Devices for the 21st Century: Stronger, Lighter, and More Energy Efficient. Advanced Materials, Vol, 23, No. 7, pp. 821-842, ISSN 1521-4095

Guth, E. \& Gold, O. (1938). On the hydrodynamical theory of the viscosity of suspensions. Physical Review, Vol. 53, pp. 322, ISSN 0031-899X

Guth, E. (1945). Theory of filler reinforcement. Journal of Applied Physics, Vol.16, pp. 20-25, ISSN 0021-8979

Hamano M. (1995). Overview and outlook of bonded magnets in Japan. Journal of Alloys and Compounds, Vol. 222, No. 1-2, pp. 8-12 ISSN 0925-8388

Hemrick, J., Lara-Curzio, E. \& Liu, K. (2004). Mechanical properties of thermally cycled nylon bonded Nd-Fe-B permanent magnets. Journal of Materials Science, Vol. 39, pp. 6509 - 6522, ISSN 0022-2461

Herbst, J.F. (1991.) R2Fe14B materials: Intristic properties and technological aspects. Reviews of Modern Physics, Vol. 63, No. 4, pp. 819-898, ISSN 0034-6861

Hono K. \& Ping, D.H. (2001). Atom probe studies of microstructural evolution in Nd-Fe-Bbased nanocomposite magnets, Materials Science and Engineering: A, Vol. 304-306, pp. 81-87, ISSN 0921-5093

Kokabi, M.; Arabgol, F. \& Manteghian, M. (2005). Nd2Fe14B Permanent Polymeric Composite Magnets, IranianPolymer Journal, Vol. 14, No. 1, pp. 71-79, ISSN 1026-1265

Lahelin, M.; Aaltio, I.; Heczko, O.; Söderberg, O.; Ge, Y.; Löfgren, B.; Hannula, S.P. \& Seppälä, J. (2009). DMA testing of Ni-Mn-Ga/polymer composites. Composites. Part A: Applied Science and Manufacturing, Vol. 40, No. 2, pp. 125-129, ISSN 1359-835X

Li, J.; Liu, Y.; Gao, S.J.; Li, M.; Wang, Y.Q. \& Tu, M.J. (2006). Effect of process on the magnetic properties of bonded $\mathrm{NdFeB}$ magnet. Journal of Magnetism and Magnetic Materials, Vol. 299, No. 1, pp. 195-204, ISSN 0304-8853

Ma, B.M.; Herchenroeder, J.W.; Smith, B.; Suda, M.; Brown, D. \& Chen, Z. (2002). Recent development in bonded $\mathrm{NdFeB}$ magnets. Journal of Magnetism and Magnetic Materials, Vol. 239, No. 1-3, pp. 418-423, ISSN 0304-8853

Maity, T.; Samanta, B.C.; Dalai, S. \& Banthia, A.K. (2007). Curing study of epoxy resin by new aromatic amine functional curing agents along with mechanical and thermal evaluation. Materials Science and Engineering A, Vol. 464, No. 1-2, pp. 38-46, ISSN 0921-5093

Makled, M.H.; Matsui, T.; Tsuda, H.; Mabuchi, H., El-Mansy, M.K. \& Morii, K. (2005). Magnetic and dynamic mechanical properties of barium ferrite-natural rubber composites. Journal of Materials Processing Technology, Vol. 160, pp. 229-233, ISSN 0924-0136

Matsuura, Y. (2006). Recent development of Nd-Fe-B sintered magnets and their applications. Journal of Magnetism and Magnetic Materials, Vol. 303, No. 2, pp. 344-347, ISSN 0304-8853 
Menard K.P. (1999). Dynamic Mechanical Analysis: A Practical Introduction, CRC Press LLC, ISBN 0-8439-8688-8, Florida

Mori, T. \& Tanaka. K, (1973). Average stress in matrix and average elastic energy of materials with missfitting inclusions, Acta Metallurgica, Vol. 21, No. 5, pp. 571-574

Otaigbe, J.U., Kim, H.S. \& Xiao, J. (1999). Effect of Coupling Agent and Filler Particle Size on Melt Rheology of Polymer-Bonded Nd-Fe-B Magnets. Polymer Composites, Vol. 20, No. 5, pp. 697-704, ISSN 0272-8397

Payne A.R. (1965). Dynamic Properties of Filler-Loaded Rubbers, In: Reinforcement of Elastomers, Kraus G., pp.69-123, Interscience Publishers, a division of John Wiley \& Sons, USA

Plusa, D.; Dospial, M.; Slusarek, B. \& Kotlarczyk U. (2006). Magnetization reversal mechanisms in hybrid resin-bonded Nd-Fe-B magnets. Journal of Magnetism and Magnetic Materials, Vol. 306, No. 2, pp. 302-308, ISSN 0304-8853

Ponte Castaneda P. (1989). The overall constitutive behaviour of nonlinear elastic composites, Proceedings of the Royal Soiety A, Vol. 422, pp. 147-171,

Radojević, V.; Talijan, N.; Grujić, A.; Ćosović, V. \& Aleksić R. (2007). Influence of composition of the magnetic composite coating on the performance of the optical fiber magnetic field sensing element. Journal of Optoelectronics and Advanced Materials, Vol.9, No. 8, pp. 2424 -2429, ISSN 1454-4164

Rodrigues, D.; Concilio, G.V. \& Landgraf, F.G. (1996). Process and Magnetic Properties of Cold Pressed NdFeB Bonded Magnets, Proceedings of the 14th International Workshop Rare-Earth Magnets and Their Applications, Vol. 1, ISBN 981-02-2762-0, Sao Paulo, Brazil, September, 1996

Sagawa, M.; Fujimura, S.; Togawa, N.; Yamamoto, H. \& Matsuura, Y. (1984). New material for permanent magnets on a base of $\mathrm{Nd}$ and Fe. Journal of Appied Physics, Vol. 55, pp. 2083-2087, ISSN 0021-8979

Slusarek, B. \& Dudzikowski, I. (2002). Application of permanent magnets made from NdFeB powder and from mixtures of powders in DC motors. Journal of Magnetism and Magnetic Materials, Vol.239, No.1-3, pp. 597-599, ISSN 0304-8853

Trout, S. R. (2000). Understanding Permanent Magnet Materials; an Attempt at Universal Magnetic Literacy, Proceedings of EMCW 2000, Cincinnati, Ohio, October, 2000, http://spontaneousmaterials.com/Papers/CW2000.pdf

Vuong, N.V.; Khanh, N.V. \& Thuy, D.M.; (2003). Simulation of the energy product (BH)max of Nd-Fe-B anisotropic bonded magnets, Physica B: Condensed Matter, Vol. 327, No. 2-4, pp. 349-351, ISSN 0921-4526

Wang, M.J. (1999). The Role of Filler Networking in Dynamic Properties of Filled Rubber. Rubber Chemistry and Technology, Vol. 72, pp. 430-448, ISSN 0035-9475

Withaeger, G. (2001). Techniques Utilized in the Characterization of Existing Materials for Improved Material Development, MSc Thesis, University of North Texas

Xiao, J.; Otaigbe, J.U. \& Jiles, D.C. (2000). Modeling of magnetic properties of polymer bonded Nd-Fe-B magnets with surface modifications. Journal of Magnetism and Magnetic Materials, Vol. 218, pp. 60-66, ISSN 0304-8853

Zhang, X.H.; Xiong, W.H.; Li, Y.F. \& Song N. (2009). Effect of process on the magnetic and mechanical properties of Nd-Fe-B bonded magnets, Materials and Design, Vol. 30, No. 4, pp. 1386-1390, ISSN 0261-3069 


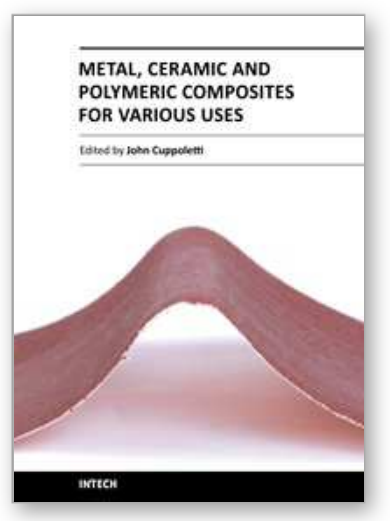

\author{
Metal, Ceramic and Polymeric Composites for Various Uses \\ Edited by Dr. John Cuppoletti
}

ISBN 978-953-307-353-8

Hard cover, 684 pages

Publisher InTech

Published online 20, July, 2011

Published in print edition July, 2011

Composite materials, often shortened to composites, are engineered or naturally occurring materials made from two or more constituent materials with significantly different physical or chemical properties which remain separate and distinct at the macroscopic or microscopic scale within the finished structure. The aim of this book is to provide comprehensive reference and text on composite materials and structures. This book will cover aspects of design, production, manufacturing, exploitation and maintenance of composite materials. The scope of the book covers scientific, technological and practical concepts concerning research, development and realization of composites.

\title{
How to reference
}

In order to correctly reference this scholarly work, feel free to copy and paste the following:

Jasna Stajic-Trosic, Mirko Stijepovic, Jasmina Stevanovic, Radoslav Aleksic and Aleksandar Grujic (2011). Magnetic and Dynamic Mechanical Properties of Nd-Fe-B Composite Materials with Polymer Matrix, Metal, Ceramic and Polymeric Composites for Various Uses, Dr. John Cuppoletti (Ed.), ISBN: 978-953-307-353-8, InTech, Available from: http://www.intechopen.com/books/metal-ceramic-and-polymeric-composites-forvarious-uses/magnetic-and-dynamic-mechanical-properties-of-nd-fe-b-composite-materials-with-polymermatrix

\section{INTECH}

open science | open minds

\author{
InTech Europe \\ University Campus STeP Ri \\ Slavka Krautzeka 83/A \\ 51000 Rijeka, Croatia \\ Phone: +385 (51) 770447 \\ Fax: +385 (51) 686166 \\ www.intechopen.com
}

\author{
InTech China \\ Unit 405, Office Block, Hotel Equatorial Shanghai \\ No.65, Yan An Road (West), Shanghai, 200040, China \\ 中国上海市延安西路65号上海国际贵都大饭店办公楼 405 单元 \\ Phone: +86-21-62489820 \\ Fax: $+86-21-62489821$
}


(C) 2011 The Author(s). Licensee IntechOpen. This chapter is distributed under the terms of the Creative Commons Attribution-NonCommercialShareAlike-3.0 License, which permits use, distribution and reproduction for non-commercial purposes, provided the original is properly cited and derivative works building on this content are distributed under the same license. 